\title{
Influencing Factors of Organizational Performance in Nepal Airlines Corporation
}

\author{
Shrijan Gyanwali ${ }^{1} \&$ John C. Walsh ${ }^{2}$ \\ ${ }^{1}$ School of Business, Pokhara University, Pokhara, Nepal \\ ${ }^{2}$ School of Business and Management, RMIT, Vietnam \\ Correspondence: Shrijan Gyanwali, School of Business, Pokhara University, Lekhnath, Kaski, Nepal. E-mail: \\ gyanwalishrijan@gmail.com / John C. Walsh, School of Business and Management, RMIT Vietnam. E-mail: \\ jcwalsh@hotmail.com
}

Received: November 11, 2019

Accepted: December 11, 2019

Online Published: December 30, 2019

doi:10.5539/ibr.v13n1p268

URL: https://doi.org/10.5539/ibr.v13n1p268

\begin{abstract}
The objective of the study is to evaluate performance influencing factors in Nepal Airlines Corporation (NAC) through mixed research method, qualitative and quantitative analysis. The primary data were obtained from in-depth interview with fifteen government and NAC executives. Secondary data were collected from Nepal Government, NAC publications and International Air Transport Association (IATA).

Revenue generation and passenger movement rate is found with average performance. Motivated employee, entrepreneurial marketing, collective leadership, ownership feeling of government and environmental support were explored as key performance factors. Sophisticated technology, airworthiness, and international standard and recommended practice were found as unique features. Lack of aircraft, unfair political influence and alienation of staffs in unionism were identified the reasons of lacking the business growth.

A performance framework is proposed which comprises entrepreneurial marketing (proactiveness, risk taking, innovativeness, opportunity focused, resource leveraging, customer intensity and value creation), collective leadership, sophisticated technology and sufficient number of modern aircrafts, service reliability and safety, and government support. The study recommends Nepal government to take ownership of NAC, and adopt fair and professional management practice rather than political quota distribution in its governing body, board of directors.
\end{abstract}

Keywords: Air transport, organizational performance, entrepreneurial marketing, international standard and recommended practice

\section{Introduction}

Organizations are trying to get better performance continuously as it is a way to grow and progress (Gavrea, Ilies \& Stegerean 2011). Organizational performance comprises the actual output or results of an organization as measured against its intended outputs (or goals and objectives). It captures organizational outcomes in three areas as financial performance, product performance, and shareholders' return (Florian, 2013). In broader sense, performance can be measured in terms of financial return and non-financial outcomes. Profit, return on investment, growth of share value, and increment of reserve and revenue are financial achievements whereas shareholders satisfaction, employ and customers satisfaction, increment of customers, market expansion, goal achievement, relevancy, efficiency and effectiveness of product and services are non-financial measures of performance (Jenatabadi, 2015).

To win the victory of present competitive world, every enterprise including airline companies are pressurized to introduce unique product/services and effective operational process. Organizational structure, resource availability, external environment, good governance, innovation and clear understanding of strategy are observed as performance influencing factors (Gavrea, Illies \& Stegerean, 2011). Change in technology, globalization, competitiveness, inconsistency on customers' preference, and emergence of e-marketing have been influencing the operational mechanism of every enterprise (Basol \& Dogerlioglu, 2014; Hansen \& Wernerfelt, 1989).

Nepal is rich with natural beauties with array of mountains including world peak Mount Everest. The forest, river, hills, gorge, plain land, animals and cultural heritage are additional attractions of Nepal. It is the country of Lord 
Buddha. Considering all these comparative advantages, tourism development remains always with priority of Nepal Government (Parajuli \& Paudel, 2014). However, the official data as of 2010/11 affirms 25 percent Nepali live under absolute poverty line (Pokhrel, 2015). Nepal is lacking behind to achieve the expected result as the country suffered from slow movement of development for last twenty years. The first ten years had conflict with armed Maoist. After ceasefire of conflict, next ten years were passed with political instability for the sake of introduction of new constitution. In the same period, the neighboring countries and most of the other developing countries like India, China, South Korea, Malaysia and Singapore took the pace of higher level of economic development.

Introduction of new constitution, Constitution of Nepal 2015, has raised the lots of hope; expectation of prosperity, growth and development of Nepal and improvement of living standard of Nepalese people. Ministry of Culture, Tourism and Civil Aviation have been supporting to Nepal Airlines Corporation (NAC) as concern Ministry of Nepal Government even though NAC has experienced ups and downs during its about its 60 years history. NAC has scope of significant growth in revenue generation, market expansion, passenger movement and cargo delivery service as the airline business is going to be double in 2035 as per the IATA's 20 years forecast in 2014 (International Air Transport Association - IATA, 2016).

Effective airline service supports for tourism development of the nation. In this regard, the research on influencing factors for organizational performance in NAC is felt essential. On the basis of importance of performance improvement in NAC, the primary aim of study is set as to investigate the influencing factors of organizational performance in NAC. More specifically, three objectives of study are to evaluate the success of Nepal Airlines Corporation's services in terms of performance standard, to examine influencing factors of organizational performance of NAC, and to explore the ways by which effective performance of NAC can be increased. The important contribution of the study is identification of key elements for improving NAC performance and recommendation of NAC performance framework as presented in Figure 7.

\section{Literature Review}

Organizational performance influencing factors, aviation business, brief overview of NAC, and conceptual framework are the key areas of literature review.

\subsection{Organizational Performance Influencing Factors}

Organizational performance indicators are described in terms of both financial non-financial achievements. Performance measures include growth and financial performance (Wiklund, 1999) whereas organization performance indicates the success of organization with regard to value creation and delivery of goods and services to internal and external customers (Antony \& Bhattacharya, 2010). The reflection of growth and success of organization is understood in terms of performance. This is the reason; enterprises are focused and give priority on their performance.

Basically, formalization and specialization lead to organizational effectiveness. On the other hand, it is reverse relationship between enlargement of organizational size and increment of organizational effectiveness. However, formalization, specialization, centralization, organizational age and size were considered as structural variable in the previously studied software company. The result suggested that software companies should stay at small scales in their organizational size to increase the performance with help of specialization and formalization (Basol \& Dogerlioglu, 2014).

Leadership style may affect the organizational performance. Previous study shows that transformational leadership is strongly correlated with higher entrepreneurial orientation, higher outcomes of leadership and higher business performance as compared to transactional leadership or passive-avoidant leadership. In case of small and medium enterprise, higher level of entrepreneurial orientation has higher level of performance output and transformational leadership with entrepreneurial orientation can contribute to higher business performance (Yang, 2006). So far as concerned for government owned enterprise like Nepal Airlines Corporation the collective leadership, executive board and its decisions has significant influence on organizational performance.

The marketing literature has introduced models of service quality, SERVQUAL and AIRQUAL to help organizations measures and enhance customer experiences. SERVQUAL has been extensively researched and applied in many industries. AIRQUAL, a model for airline industry, has been developed but applied only in Cyprus. Moreover, AIRQUAL scale lacks validity, as its development process is incomplete (Alotaibi, 2015).

Different studies have shown that various elements of entrepreneurial marketing have significant positive impact on organizational performance (Hacioglu, Even, Even \& Celikkan, 2012; Hamali, 2015; Ma, Kim, Heo \& Jang, 2012; Mwangi \& Bwisa, 2013; Sarma, Septiani, Dewi \& Siregar, 2013). In today's competitive world, the 
survival of organizations depends on innovation, creativity and entrepreneurship (SaeediKia, 2007) and those firms with a stronger entrepreneurial orientation have better performance than their counterparts in the same industry (Moghimi \& Ahmadpour, 2007). Entrepreneurial marketing is being practiced to address the unpredictable and inconsistent market situation that is created due to the technological advancement, changing need and demand of customers, and competitive situation of present global marketing practice. Six factors named growth orientation, opportunity orientation, market immersion, two-way contacts with customers, value creation through relationship and alliance, and informal marketing research are underlining behavior of entrepreneurial marketing (Kilenthong, 2011). Seven elements of entrepreneurial marketing that leads the enterprise success are proactiveness, opportunity focused, calculated risk taking, innovation-oriented, customer intensity, value creation and resource leverage (Becherer, Helms \& McDonald, 2012; Morris, Schindehutte \& LaForge, 2002).

Regarding the organizational performance with respect to governance, the presence of several regulations and weak corporate governance were investigated as a contributing factor to the poor performance (Dragnic, 2014). Generally, corporate governance has positive impact on all the performance indicators of an organization (Mudashiru, Bakare, Babatunde \& Ishmael, 2014). Six dimensions of governance that were investigated by World Bank are voice and accountability, political stability and absence of violence, government effectiveness, regulatory quality, rule of law, and control of corruption (Chandrasorn, 2014).

Jackson (2015) compared the key Performance Indicators (KPIs) with compass which helps to take right path toward the strategic goals. He presented 18 KPIs under finance metrics - 7 (profit, cost, revenue, cost of goods sold, bay sales outstanding, sales by region and expenses vs. budget), customer metrics -5 (customer lifetime value - getting from a long term customer relationship, customer acquisition cost, customer satisfaction and retention, net promoter score/ customers recommendation to someone and number of customers), process metrics - 3 (customer support tickets, percentage of product defects and efficiency measure), and people metrics -3 (employee turnover rate, percentage of response to open position and employee satisfaction).

According to organizational performance framework (Mitchell, 2002), the performance is affected by organizational motivation, influence of external environment and organizational capacity to achieve the desired result. Four buckets of performance are relevance, effectiveness, efficiency and financial viability and these measures are affected by organization's motivation, its capacity, and its interaction with the external environment as shown in Figure 1.

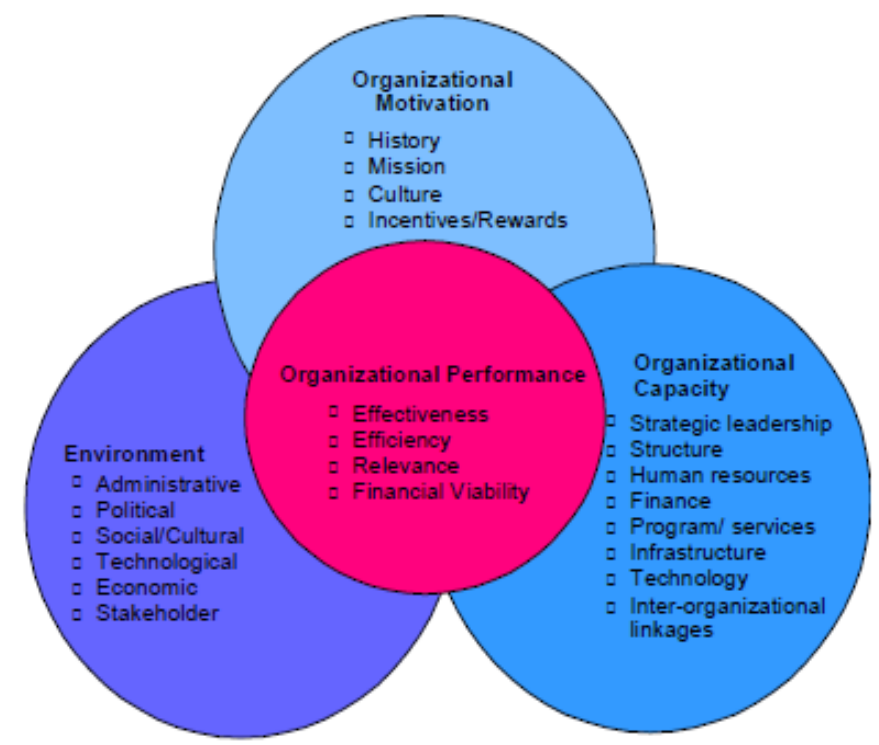

Figure 1. Organizational Performance Framework (Mitchell, 2002)

Right Management (n.d.) presented the integrated framework for enhancing organizational performance in terms of productivity and profitability. Organizational effeteness framework includes seven elements named strategy, structure, capacity and capability, leadership, people system and process, cultural and value, employee management and customer experience. These key elements of organizational performance are important influencers of employee engagement which leads to productivity and profitability as presented in Figure 2. 


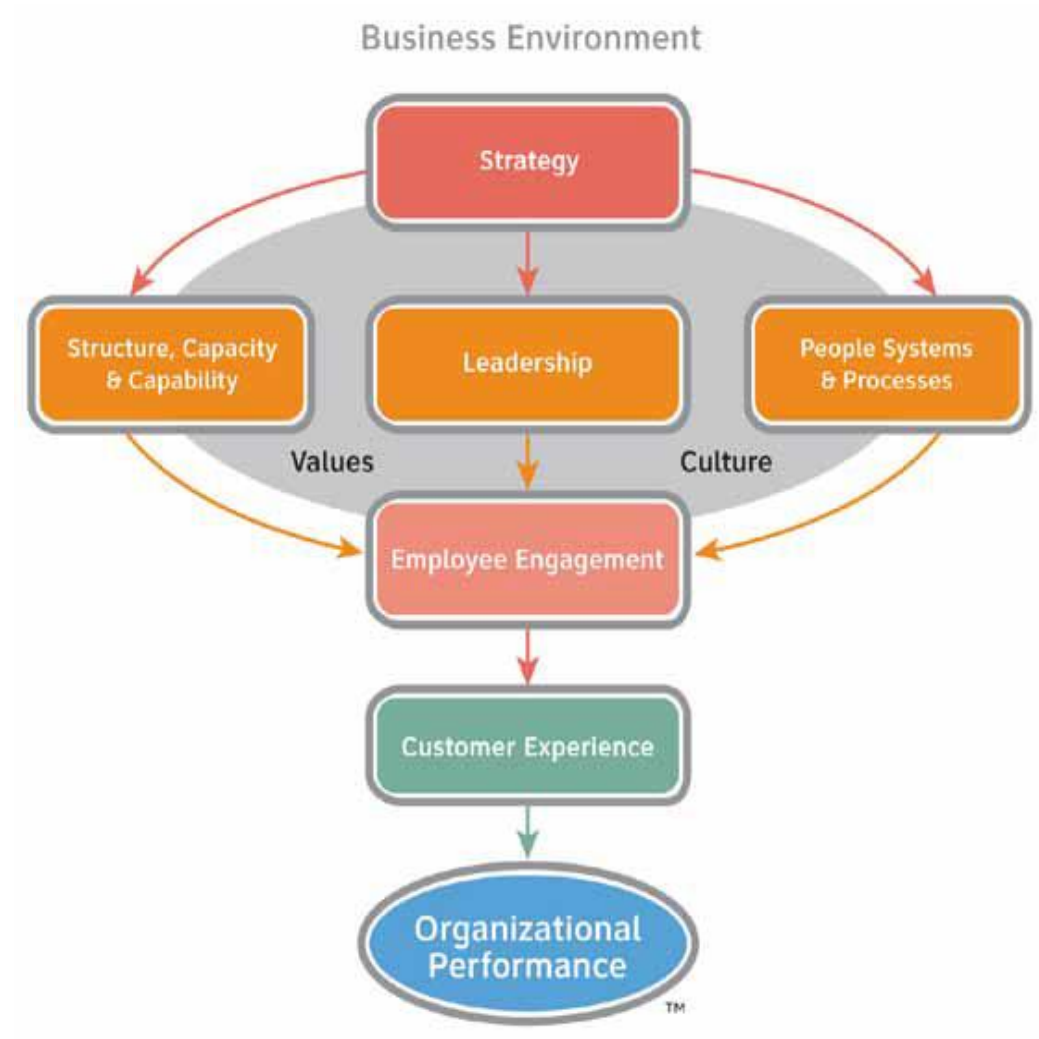

Figure 2. Right Management's organizational effectiveness framework

Gavrea, Ilies and Stegerean (2011) conducted research with Romanian manufacturing industries and proposed a model of organizational performance with three elements. First, structural issues which is related to company size, age and purpose. Second, the variables used to analyze the sampled firm which includes external environment comprising competition, customers and suppliers; and internal environment which is reflected by company strategy, leadership, employee, quality of services, performance measuring criteria, innovation and development of information technology. Third is quantifying the organizational performance on the basis of its results.

Initially, output variables (revenue) and input variables (equipments) were basic means of airlines business performance. Load factor, market share, operating profit, material, energy, labour, capital, customer satisfaction, financial indicators, advertisement expenses, and GDP are common elements to evaluate the airlines performance (Ismail \& Jenatabadi, 2014).

\subsection{Aviation Business}

The history of aviation beginning with the first drawing and flying items goes back to the fifteenth century even though hot air balloons and kites were in practice since ancient time in China (Wittmer, Bieger \& Muller, 2011). The significant attempt began with Orville and Wilbur Wright's first flight on December 17, 1903. With continuous research and design efforts for four years, the first powered flight heavier than air machine, a 120-foot, 12-second, at Kitty Hawk, North Carolina, was launched on the same day. Leon Delagrange was first passenger with French Pilot Henri Farman from a meadow of Paris in 1908. First American airplane passenger was Charles Furnas who flew with Orville Wright at Kitty Hawk later that year. First time, in January 1, 1914, fixed wing air service was scheduled from St. Petersburg to Tampa, Florida (Barata \& Neves, 2017; Petrescu, Aversa, Akash, Bucinell, Corchado, Berto, Mirsayar, Apicella and Petrescu, 2017).

Chicago Convention, the convention on international civil aviation, established the aviation rules and regulation that was signed on December 7, 1944 and became effective in since 1947. On the same day, International Civil Aviation Organization (ICAO) was formalized and it has been managing all the rules and requisites of aviation industry as provisioned under the 'international standards and recommended practice.' Presently, 19 annexure (Annexure 1 - Personal Licensing, 2 - Rules of the Air, 3 - Meteorological Services, 4 - Aeronautical Charts, 5 - 
Units of Measurement, 6 - Operation of Aircraft, 7 - Aircraft Nationality and Registration Marks, 8 Airworthiness of Aircraft, 9 - Facilitation, 10 - Aeronautical Telecommunications, 11 - Air Traffic Services, 12 Search and Rescue, 13 - Aircraft Accident and Incident Investigation, 14 - Aerodromes, 15 - Aeronautical Information Service, 16 - Environmental Protection, 17 - Security, 18 - The Safe Transportation of Dangerous Goods by Air, and 19 - Safety Management) are included in international standards and recommended practices (International Civil Aviation Organization, 2007; Mackenzie, 2010).

European Union airspace established the deregulation in early 1990 and focused on sensitivity of safety issue as a most essential. It encouraged for the open skies agreements, and code sharing and alliance practice became more common that has greater impact on business transaction. The budget airlines services in shorter routes have given substantial discount to passengers and it has greater impact for increasing the number of airlines passengers.

Airlines of the world transported 3.5 billion people and 51 million metric tons of cargo safety in 2015 . Every day in global network, nearly 10 million people have managed a fleet of 26,000 aircrafts averaging 1000,000 flights of 51,000 routes (Tyler, 2016).

\subsection{Nepal Airlines Corporation}

In July 1958, Royal Nepal Airlines Corporation (RNAC) presently called Nepal Airlines Corporation (NAC) was established as first airlines services in Nepal which is a national flag carrier airline of Nepal. Douglas DC-3 was first aircraft and used to serve domestic routes and few destinations to India. It is a government owned public enterprise under the Ministry of Tourism and Civil Aviation as incorporated according to Nepal Airlines Corporation Act 2019 BS (Nepal Government, 2010). Civil Aviation Authority of Nepal (CAAN), an authentic body to provide necessary support for aviation business, was established in 2053 BS. CAAN introduced the Civil Aviation Rules 2058 BS for smooth operation of aviation business in Nepal (Civil Aviation of Authority of Nepal, 2013).

At the present, Nepal airlines flies to 8 international cities (within 6 countries) including Delhi, Mumbai, Banglore, Bangkok, Kuala Lumpur, Dubai, Doha and Hong Kong through Tribhuvan International Airport Kathmandu. NAC flies to 25 domestic destinations. It comprises twelve departments named Finance, Human Resource, General Service and Property Management, Continuing Airworthiness Management, Engineering Maintenance, Quality Assurance and Flight Safety, Operation, Ground Support, Corporate, Commercial, Customer Service and Internal Audi Department. Currently 2,500 employees have been working in NAC (Nepal Airlines Corporation, 2016).

NAC has always been a barometer for the state of the nation, so it is no great surprise that a perfectly good airline has in the past 12 years been brought down to its knees through political interference, mismanagement and corruption. The most glaring example of graft was the hiring of a general sales agent (called Dhamija) for Europe in 1995 under the pressure from politicians which caused the airlines losses worth nearly Rs. 400 million (Bhattarai, 2002). The airline was on growth stage till 1990 which was also marked as golden era in the history of airline. The airline had spread its wings from Japan in east and Europe in west in addition to about 40 domestic operations within the country. But the growth stage could not last for long. NAC decided to stop its Europe operation in 2001 (Frankfurt, London and Paris from 1987 to 2001 for about 13 years and flights) to Osaka and Shanghai were also withdrawn from NAC's network from 2007 which was operated from 1994 (KC, 2010).

It is suspected that the political leaders hired the Lauda air by grounding the existing aircrafts for 90 day to take personal benefit. Because of aircraft hiring contract, NAC got 90 million dollar loss where as Boeing 757 could be purchased on 70 million dollar (Shrestha, 2011). NAC's continuous upward growth was turned to downwards with the political intervention. The sale of two Boeing-727 and withdrawn of flights of Europe without any homework in 2002, Nepalese travelers compelled to use foreign airlines with about double fair (Shah, 2012). Suga Ratna Kansakar, Executive Chairman of NAC, signed a memorandum of understanding with Airbus to purchase new aircrafts in November 2009. Wide-body 330 and the narrow body 320 were to have delivered in two years. But after sending the advance $\$ 750,000$, Kansakar was jailed as being blamed for financial irregularities and not following procedures. However, the deal was revived later. But the order was changed to two A320s with the Employees' Provident Fund chipping \$ 106 million for the purchase. If the original deal had gone through, NAC would today already be ferrying Nepali workers back and forth from Malaysia and Qatar and ensuring that their hard-earned money stayed at home (Gurung, 2013).

The blame goes to greedy and selfish politicians who put their own interest ahead of the interest of the country, its people and its flag carrier. The tragedy is that we have learnt nothing from the mistakes of the 1990s that led 
to the deterioration of the airline. The induction of eight new aircrafts in the next two years has restored hope and confidence that it could rebuild a once proud company. The Nepal Airlines management was attacked for pushing a plane that had a questionable safety record, and the opposition was so fierce that negotiations nearly collapsed. Managing Director Madan Kharel, however, persevered and overcame intense pressures to get the contract back on track. Some of the stakeholders suggested not buying a plane unless it is safe and its airworthiness is beyond doubt. To be sure, adding new equipment will not solve the problem if the airline's management remains weak and exposed to political interference. To turn Nepal Airlines into a service-oriented, sustainable business, it needs to be cleaned up: its management streamlined, pilots and engineers made more productive, and the company freed from the clutches of rival unions and the government (Lama, 2014).

The European Commission placed Nepal as one of the 18 nations banned from flying to EU. This measure came into force after the CAAN (Civil Aviation Authority of Nepal) failed to rectify safety short-comings. EU had blacklisted, placing restriction on NAC for the first time on December 5, 2013 after ICAO designated the significant safety concerns about the country's aviation sector citing non-compliance with ICAO protocols in eight critical elements ranging from flight operation to air accident investigation (Himalayan News Service, 2016).

Three years improve plan - 2072 has made provision for purchasing new aircrafts, revision and update of policies, improving e-ticketing and online ticketing system, internal management improvement, human resource management and skill development, property management and improvement in financial system, international market expansion, removal of NAC from EU air safety list and implementation of effective controlling and evaluating system (Subedi, 2016).

Airline service has direct impact on tourism business, which seems attractive for Nepal. However, the whole range of socio-cultural, economic, technological, legal policies including bilateral air agreements greatly affects the appeal, attractiveness, competitiveness and sustainability of tourism destination (Bista, 2009).

Some positive impact of Nepal government's decisions have been found in aviation business as the government took decision on 2008 to launch a national tourism campaign named 'Nepal Tourism Year 2011' that supported to increase the number of visitors in Pokhara (Parajuli \& Paudel, 2014).

\subsection{Conceptual Framework}

On the basis of overview of literature organizational perfomrance can be measured in interms of efficiency, effectiveness, relevance with help of financial and non-financial indicators in broader perspective. Internal and external environment, organizational culture, strategy, leadership, organizational structure, human resources, environmental support, physical resources, good governance and entrepreneurial marketing that comprise proactiveness, risk taking, innovativeness, opportunity focused, resource leverage, customer intensity and value creation have significant impact on organizational performance.

The NAC performance is a dependent variable for this study whereas independent variables are revenue growth, international passenger movement (market share), passenger load factor, and change in GDP and NAC Revenue. Hence, NAC performance has been evaluated on the basis of four independent variables.

\section{Research Method}

After receiving the verbal consent from Ministry of Culture, Tourism and Civil Aviation, and NAC corporate office, research work was stated. Methods of research process are presented in two areas as data collection and analysis of result. Major responsibilities mentioned in Nepal Airlines Corporation Act 2019 (1963 AD) with its updated version 2066 (2010 AD) are the basis evaluation parameters (Nepal Government, 2010). Revenue, load factor, passenger movement and GDP growth rate are main indicators to measure the NAC performance as these factors were identified suitable for quantitative data analysis of airlines business (Ismail \& Jenatabadi, 2014). Indicators of qualitative data were prepared on the basis of previous studies and verifying them with experts' opinion before organizing the in-depth interview.

In-depth interview checklist, the letters from university to concern authorities for data and list of interviewee were prepared during the preparatory stage of study. Key points of check list that were covered during the in-depth interview were NAC performance influencing factors, unique features of NAC, entrepreneurial marketing practices and their effect on NAC performance, the major problems that have been facing by NAC and the best actions for improvement. Mixed research method, comprising quantitative and qualitative analysis, was designed for the study.

\subsection{Data Collection}

Qualitative information was collected from primary sources by administration of in-depth interview and face to 
face interaction with fifteen executives/ officers of concern organizations/ departments. It was conducted within three months covering the period from August to October 2016. Fifteen executives/ officers of Nepal Airlines Corporations (NAC), Ministry of Civil Aviation, International Association of Air Transport (IATA), representative of International Civil Aviation Organization (ICAO), and Civil Aviation Authority of Nepal (CAAN) were approached for primary data. A checklist of questionnaire was prepared for conducting the in-depth interview. After taking the consent, audio record was made for most of the participants. The interview was conducted for minimum 12 minutes to maximum 46 minutes. Key points of interview and face to face interaction were recorded in the note copy for rest of the participants. The transcript of audio record and key note points of interview were translated by maintaining the accuracy of ideas as much as possible whereas most of the interviewee spoke in Nepali medium.

Quantitative data were obtained from secondary sources such as annual reports of Nepal Airlines Corporation, Ministry of Culture, Tourism and Civil Aviation, Nepal Rastra Bank, and IATA. Some other sources of information for both qualitative and quantitative analysis were interaction with staff while visiting the concern office, and published information in the form of annual report, news and articles.

\subsection{Analysis of Data}

Quantitative analysis has been made in terms of annual growth of revenue, load factor, passenger movement and contribution on GDP. Results of quantitative analysis are presented in the figures. Content analysis was done for qualitative data. During this process, interview transcripts were labeled, categorized and given the theme with appropriate headings. The leadership (collective leadership), entrepreneurial marketing, motivated employee, external environment, government support, modern aircrafts, airworthiness, international standard and recommended practices, and higher amount of investment were identified as NAC performance influencing factors. The name of interviewee has been denoted by A, B, C, .. to maintain the standard norms of confidentiality. Confirmatory approach was used to ascertain the accuracy of result from two methods quantitative and qualitative analysis.

\section{Results and Discussion}

NAC performance is evaluated in both quantitative and qualitative methods. NAC performance model has been presented on the basis of study result.

\subsection{Quantitative Analysis}

NAC performance is evaluated with help of quantitative data in terms of revenue generation, passenger movement and NAC market share, achievement of passenger load factor, and change in GDP and NAC Income.

\subsubsection{Revenue Growth}

Yearly revenue NAC and average revenue of aviation industry in world for 10 years, covering from 2006 to 2015, is presented. NAC has generated highest revenue with $65.2 \%$ (NRs. 3.3 Billion to NRs. 5.5 Billion) growth rate in 2009 that was the reason of Nepal government's decision on 2008 'Nepal Tourism Year 2011' (Parajuli \& Paudel, 2014). In case of aviation industry, highest growth rate with $18.4 \%$ (\$ 476 to $\$ 564$ Billion) was found in 2010. NAC suffered negative growth by $41.36 \%$ (NRs. 5.7 Billion to NRs. 3.3 Billion) in 2008 and industry average has $16.5 \%$ ( $\$ 570$ to $\$ 476$ Billion) negative growth rate in 2009 (International Air Transport Association, 2016; Nepal Airlines Corporation, 2016). The trend of revenue is depicted in Figure 3 as follows. 


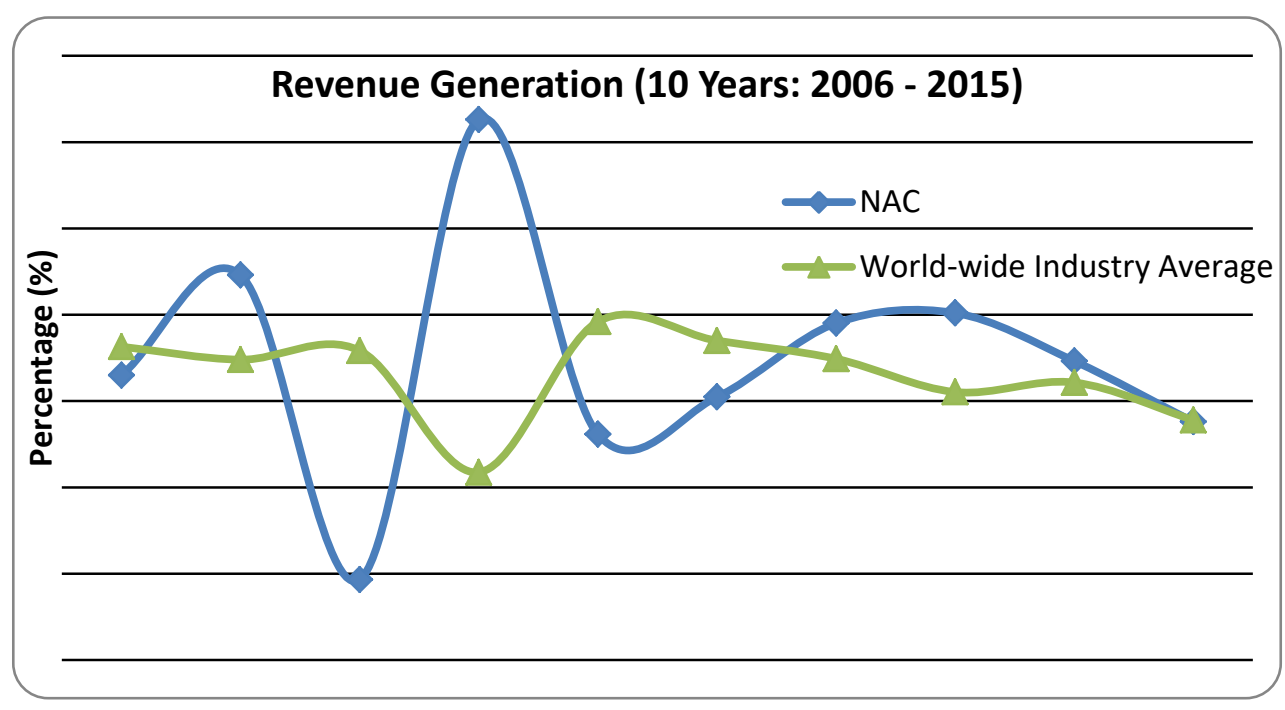

Figure 3. Trends in Revenue Growth

Source: NAC Annual Reports (FY 2062/63 to 2071/72) and IATA Economic Performance Forecast (June 2016).

\subsubsection{International Passenger Movement and NAC Market Share}

International passenger movement in Nepal is analyzed for 2 years (2015 and 2016). More than thirty airlines operated their flights during this period through Tribhuvan International Airport. The market share captured by NAC was 7.88 percent $(253,658$ out of 3,217,162 passengers) in the year 2015 and 10.95 percent $(384,327$ out of $3,510,742$ passengers) in the year 2016 (Nepal Government, 2016). The share of passenger movement by competing airlines is presented in Figure 4.

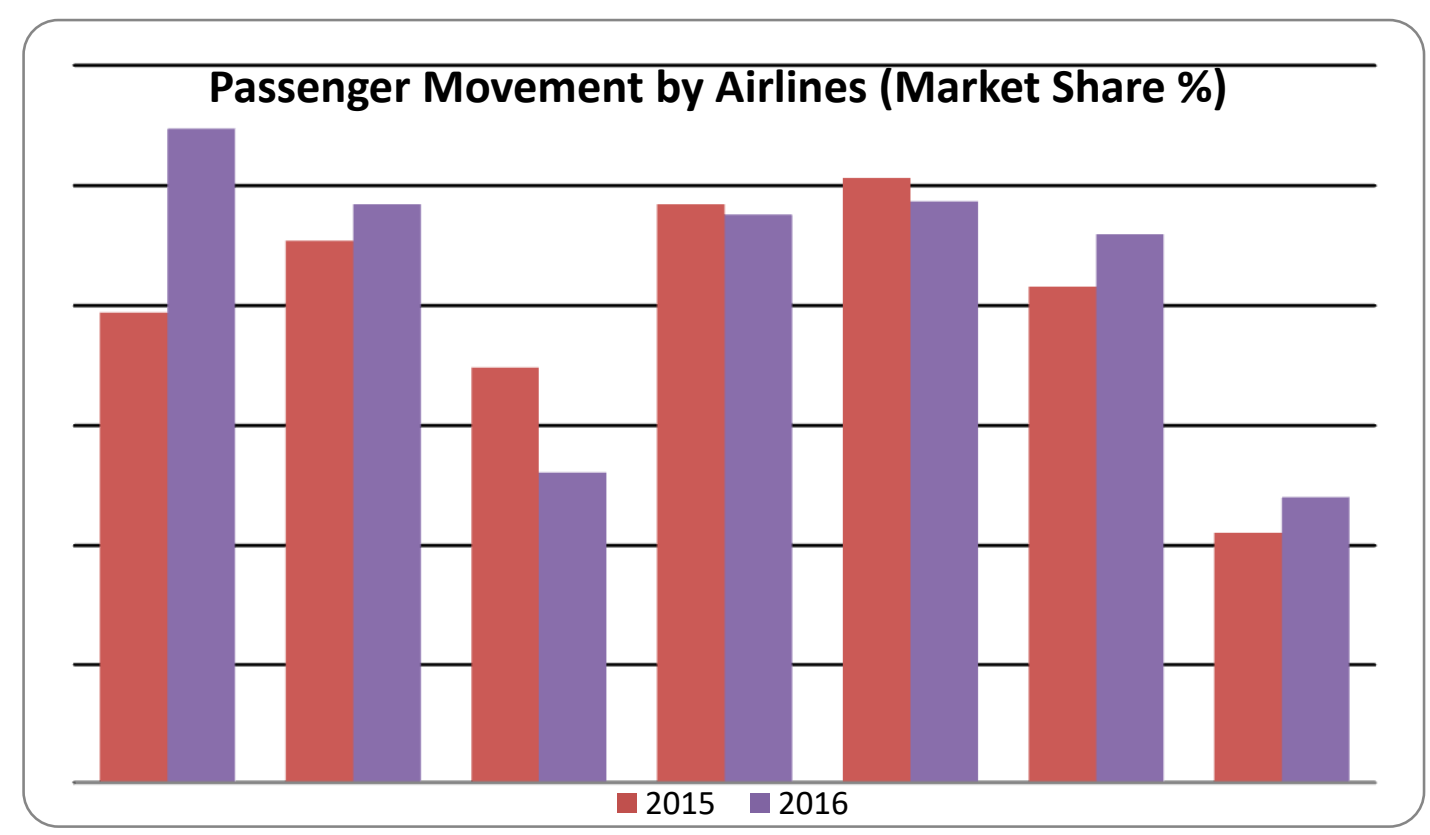

Figure 4. Share of International Passenger Movement by different Airlines in Nepal

Sources: Nepal Tourism Statistics 2016, Ministry of Culture, Tourism and Civil Aviation (MoCTCA), Nepal Government.

\subsubsection{Achievement of Passenger Load Factor}

The passenger service load factor of international flights achieved by NAC and other airlines for 10 years (2007 to 2016) has been analyzed. NAC has achieved highest load factor (83\%) in 2014 and it has lowest passenger 
load factor (69\%) in 2009. Likewise, aviation industry average load factor is found highest (80.4\%) in 2015 and lowest $(76.1 \%)$ in 2008 (International Air Transport Association, 2016; Nepal Airlines Corporation, 2016). The passenger load factor of NAC and industry average is depicted in Figure 5.

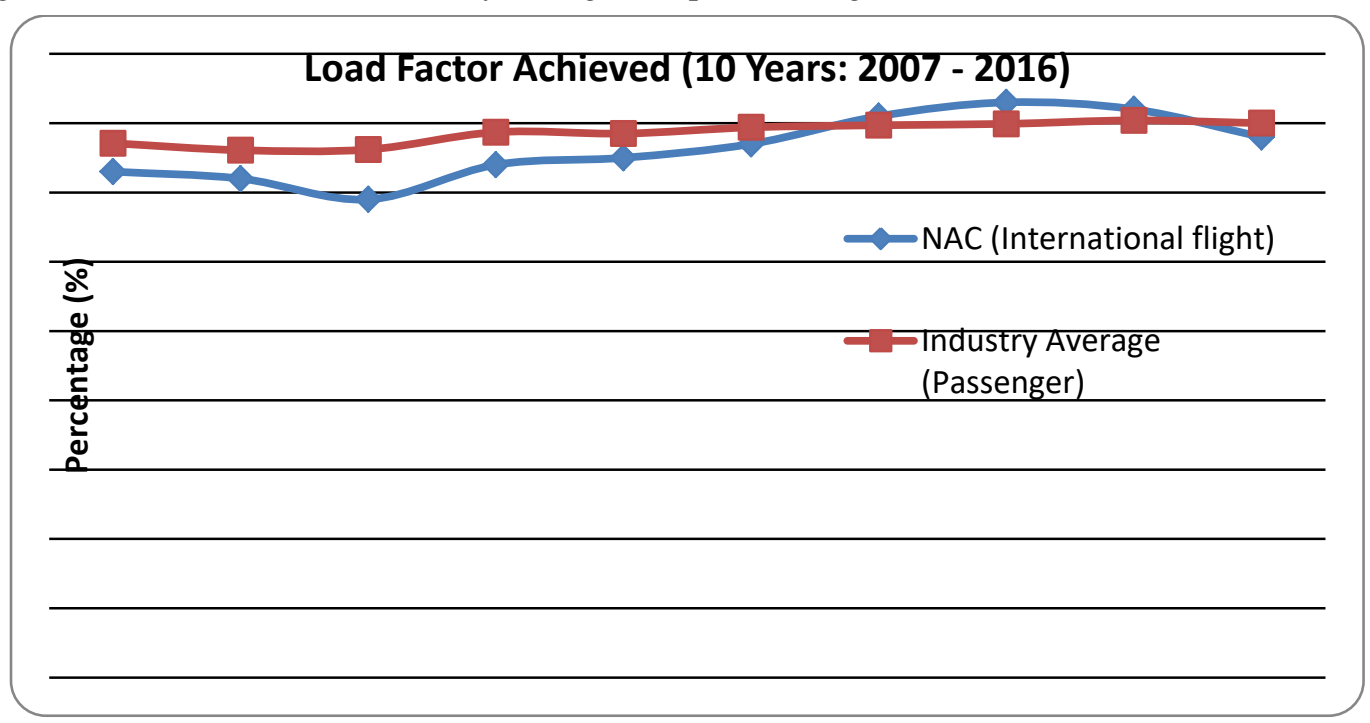

Figure 5. International Passenger Load Factor

Source: NAC Annual Reports (FY 2063/64 to 2072/73) and IATA Economic Performance of the Airlines Industry (Forecast June 2016).

\subsubsection{Change in GDP and NAC Income}

The percentage of revenue change of NAC is compared with GDP growth rate of Nepal and average GDP of the world-wide nations. The GDP of Nepal, World-wide GDP and changing percentage of NAC revenue for 8 years, 2008 to 2015, is presented. Nepal has positive GDP rate with maximum (6.1) in 2008 and minimum (3.0) in 2015. Average world GDP rate was maximum (4.1) in 2010 and minimum with negative value (-2.0) in 2009 . The NAC revenue rate is found with highly inconsistent as positive growth (65.2) in 2009 and negative value (-41.4) in 2008 (International Air Transport Association, 2016; Nepal Government, 2016; Nepal Rastra Bank, 2015). The changes in GDP rate of Nepal and world-wide average and change in NAC revenue rate is depicted in Figure 6.

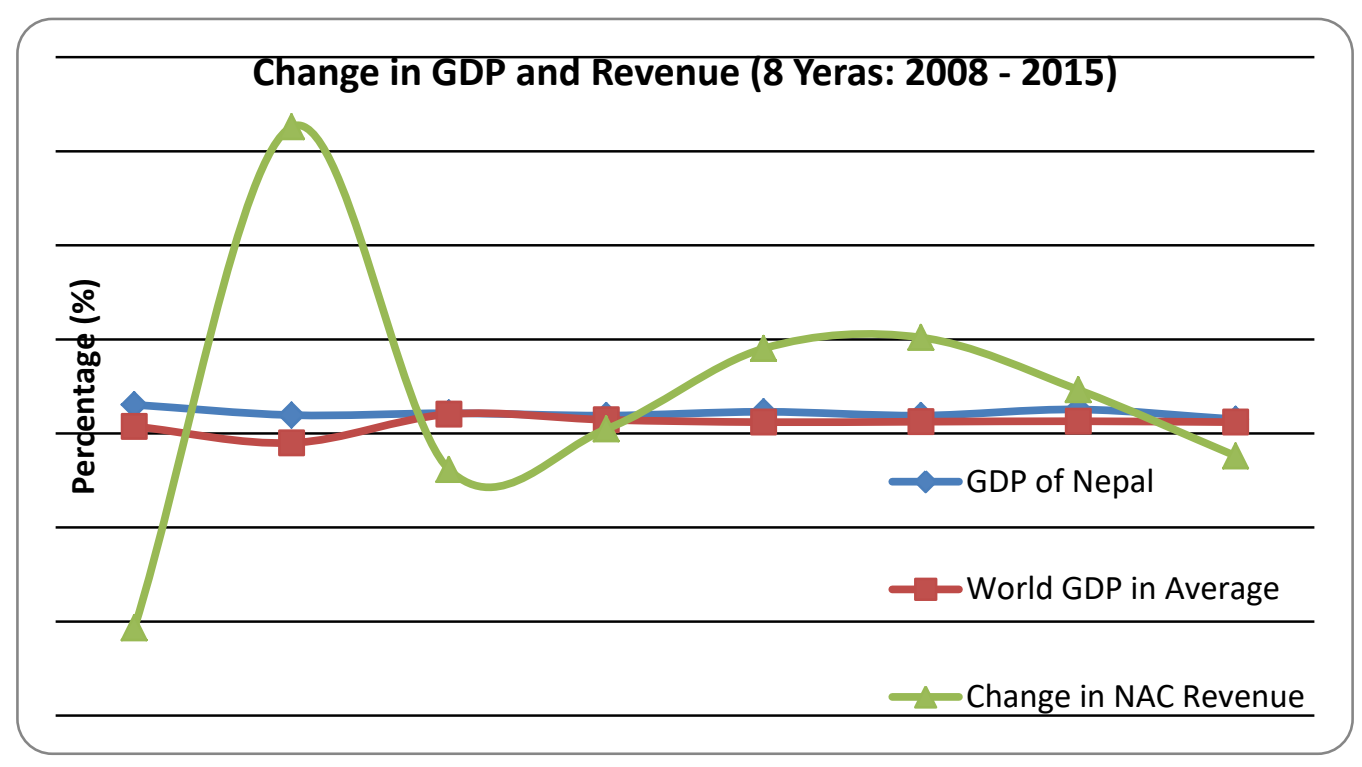

Figure 6. Changes in GDP and NAC Revenue

Source: Macroeconomic Indicators of Nepal; Nepal Rastra Bank, 2015; NAC Annual Reports (FY 2064/65 to 2071/72); and IATA Economic Performance of the Airlines Industry (Forecast June 2016). 
Revenue increment, load factor, passenger movement and GDP growth of NAC, and world-wide aviation business shows fluctuating movement. However, the movement direction of NAC and world-wide aviation business has gone to similar direction. Therefore, NAC performance is evaluated as satisfactory.

\subsection{Qualitative Analysis}

Qualitative analysis has been made to identify the NAC performance influencing factors and its unique features so that the proper direction can be determined. Collective leadership, entrepreneurial marketing, motivated employee, external environment, ownership feeling and strong support from government, and availability of aircrafts were explored as the influencing factors of NAC performance.

\subsubsection{Leadership}

The leadership is important to lead the team members for achieving organizational objectives. Collective leadership is the executive body i.e. board of directors, who decides and provides the guidance for overall management of NAC.

While talking about leadership two aspects as individual leadership and collective leadership are to be taken in to consideration. The Managing Director and his personal qualities such as vision, thought, working style, honesty and values have impact on organizational success. More than this, the decisions of Board of Directors (collective leadership) is a significant element for better performance of NAC.

Respondent 'A'

The leadership is to be handled by the management professional or the person who has experience of airline business. Airline business is complicated and frazil. The executive board of public enterprise like NAC should have farsightedness while taking the decision so that the changing situation may be handled tactfully.

Respondent 'B'

\subsubsection{Entrepreneurial Marketing}

Entrepreneurial marketing is described the visionary marketing actions of entrepreneurs which comprises proactive approach, opportunity focus, risking taking behavior, innovative orientation, customer intensity, resource leverage and value creation.

The study identified the some elements of entrepreneurial marketing which have been implementing in NAC. These factors are reliability, punctuality, service quality, customer intensity and networking. Promotional scheme, price discrimination, integrated communication, proactive approach, minimizing risk, image of national flag carriers and resource leverage are entrepreneurial marketing attempts of NAC.

To win the competitive market NAC has been offering additional benefits, promotional attempts with innovative marketing, good quality food and attention for maintaining the safer flight schedule as a basic requirement of airlines business.

Respondent ' $A$ '

Airline service is most perishable in nature as similar to the market of fruits and vegetables. All the seats should be booked earlier than air flight. All expense are incurred even it flies with very few passengers. Standard practices of marketing management are not applicable in aviation business. To satisfy and improving passengers loyalty, airlines business should maintain the reliability and punctuality on flight schedule, offering the mileage point to frequent travelers, connection flight service and extra benefits like upgrading the seats to higher class and hotel room facility at the destination. Higher rate of commission, friendliness and partnership relation are important to satisfy the ticket.

Respondent 'B'

Different promotional schemes like discounting the price, seasonal offers and image of national flag carrier. Informal and integrated communication, social network through face-book and twitter has been practiced by NAC. It adopts proactive approach for selling the seats by visiting the sales agents and conducting the regular meeting with them. To minimize the internal risk NAC has been adopted on-line ticket booking system, regular meeting of executive committee, and following the rules and guidelines of CAAN and ICAO.

Respondent ' $\mathrm{D}$ '

Customer satisfaction and their loyalties can be improved by reliable service. The air accidents may be forgotten slowly within few months and year but reliability on service comes in the mind of customers while purchasing the air ticket. NAC aims to cover world market through entrepreneurial marketing like connection flight and 
code-sharing partnership with other strong airlines after maintaining its reliable service, sufficient number of aircrafts, and customer friendly and responsive staffs.

Respondent 'E'

\subsubsection{Motivated Employee}

One of the important influencing factors of NAC performance was identified as efficient human resources. Physical resources like machine, computer and robot are handled, operated and commanded by human resource. To motivate the staff, NAC have been offering training, reward and appreciation properly.

Who make the airplane? Who repair and maintain the aircrafts? Who serve the customers? Who provide computer commands? Who fly the airplanes? Certainly, the single answer is staff members or called human resources. The employee should be motivated properly so that they will be responsible for their duties instead of blaming to others and protesting for additional benefits. NAC have been organizing staff training regularly to make clarity of organizational goal, objectives and job responsibility. However, regular training in aviation sector is mandatory, as pilots should participate in refresher training within every six months. Regarding the motor driving sector such training are not found even at the license renewal time, 5 years interval.

Respondent 'A'

\subsubsection{Environmental Support}

The study investigated that environmental support was one performance influencing factor in NAC.

The comparison can't be made between Nepal Airlines and Thai Airways even they were started at a same time as national flag carrier. Nepal and Thailand has different economic status and development pattern. Appropriate environment is not created to the Managing Director of Nepal Airlines as there is no certainty of tenure of service. Government appoints 'hamro manche' (our person) rather than' ramro manche' (good person). Supportive environment (internal and external) is essential to improve the NAC performance.

Respondent ' $\mathrm{B}$ '

\subsubsection{Strong Support and Ownership Feeling of Government}

The performance of NAC is influenced by the parental role of Nepal government and appropriate support in appropriate time.

In case of government owned enterprise, non-professional directors may be appointed due to political influence. The executives who have no sufficient knowledge in airline business will not be able to lead the organization. Considering the sophisticated technology and distinct features of airline service, professional management is to be practiced. Nepal government is not able to attract the professional managers in NAC as the professionals don't ask for post and they don't work only for political interest by compromising the professional ethics. In this phenomenon, NAC is lacking the professional managers and aviation business has been suffering from management crisis in different time interval.

Respondent 'B'

Nepal government influences major decisions of NAC as it is a public enterprise. Nepal Airlines was not able to purchase airlines for 30 years due to dependency on government decision. Some posts are remaining vacant due to unavailability of qualified candidates as some seats are reserved to schedule class. Regarding the decision for purchasing Airbus, NAC authorities were sent to jail to investigate crime abuse beyond their authority. Eventhough they got clean cheat the buying decision was already delayed. NAC has borrowed loan for purchasing the aircraft with 12\% interest from Karmachari Sanchaya Kosh (citizens' investment fund) whereas commercial banks have been providing vehicle loan on 6\%. It reflects the poor ownership of Nepal Government.

Respondent 'E'

\subsubsection{Availability of Aircrafts}

The performance NAC is influenced by the availability of modern aircrafts.

For international flights, NAC has 4 aircrafts including 2 Boeings (757) and 2 Airbuses (320) at present. After a long gap, two airbuses were purchased last years and they have maintained $98 \%$ reliability and $99 \%$ punctuality on the flight. Old aircraft (Boeings) has high maintenance cost as they were purchased 30 years ago. Repairing parts are to be imported from abroad and it takes 2-3 days. Indigo, Indian private airlines, places the order of 100 aircrafts at a time. Thai Airways purchase 15-20 aircrafts every year. Singapore Airlines runs aircrafts for 5 years which supports to minimize their maintenance cost. Airlines companies earn by flying the aircrafts. NAC 
have no sufficient number of aircraft which is prerequisites of aviation business. It is not justice telling to walk ahead tightening the both legs.

Respondent ' $E$ '

\subsubsection{Unique Features of Airlines Business}

Respondents were interviewed regarding the special features of aviation business. Sophisticated technology, airworthiness, high investment, international standard and recommended practice were revealed as unique features of airlines business.

Airlines business is based on sophisticated technology. The plane is to be certified technically through engineering department before taking the flight. In the absence of certificate of technical assurance no airplane can fly even it is newly tested from manufacturing point of view. Airworthiness is one another unique features of airline business which is important for successful operation. Airworthiness can be maintained by technical soundness of crafts, implementation of aviation regulations and customer satisfaction through safe and flight on time. Aviation industry has specific guidelines for different activities. For example, installation of the electric switch, notice placement area, arrangement of seats, exit information, use of fonts, words, language etc. need to be made orderly as guided by operational specification.

Respondent 'A'

High investment and synchronizing minimum cost are the unique features of aviation business. Smaller rate of profit is one of features of airline business and it is said that if you want to be a millionaire open an airline, for that you have to be a billionaire'. One of the major cost elements in airline business is fuel which holds about 30 to 45 percentage of total operational cost. Some major elements of cost are maintenance, manpower, overhead etc. IATA reported that air line business earned paper thin margin in 2015 from razor thin margin in 2014 because of reduction on fuel cost.

Respondent ' $\mathrm{B}$ '

Aviation business is operated as accordance to International Standard and Recommended Practices introduced by International Civil Aviation Organization (ICAO). NAC provides air transport services following the provisions and guidance of NAC Act 2019, NAC Employee By-rules, NAC Finance By-rules, Civil Aviation Act 2015, Airlines governing rules/manuals, and decisions of Nepal Government. Civil Aviation Authority of Nepal (CAAN) is an authentic body for providing necessary guidance and control to the airlines companies of Nepal. CAAN was established in 2053 BS and it is a member of ICAO. International Air Transport Association (IATA) is a trade association of airlines that focuses on making air traffic businesses safe, secure, reliable and efficient.

Respondent ' $F$ '

Outcome of qualitative analysis indicates that NAC needs to focus on entrepreneurial marketing and improving the effectiveness of collective leadership. Employees are to be motivated, and strong support from government is essential. To maintain the reliability and punctuality of flight schedule NAC should have sufficient number of modern aircrafts.

\section{NAC Performance Framework}

After having the review of literature and study of quantitative and qualitative data analysis NAC performance framework is prepared in Figure 7. 


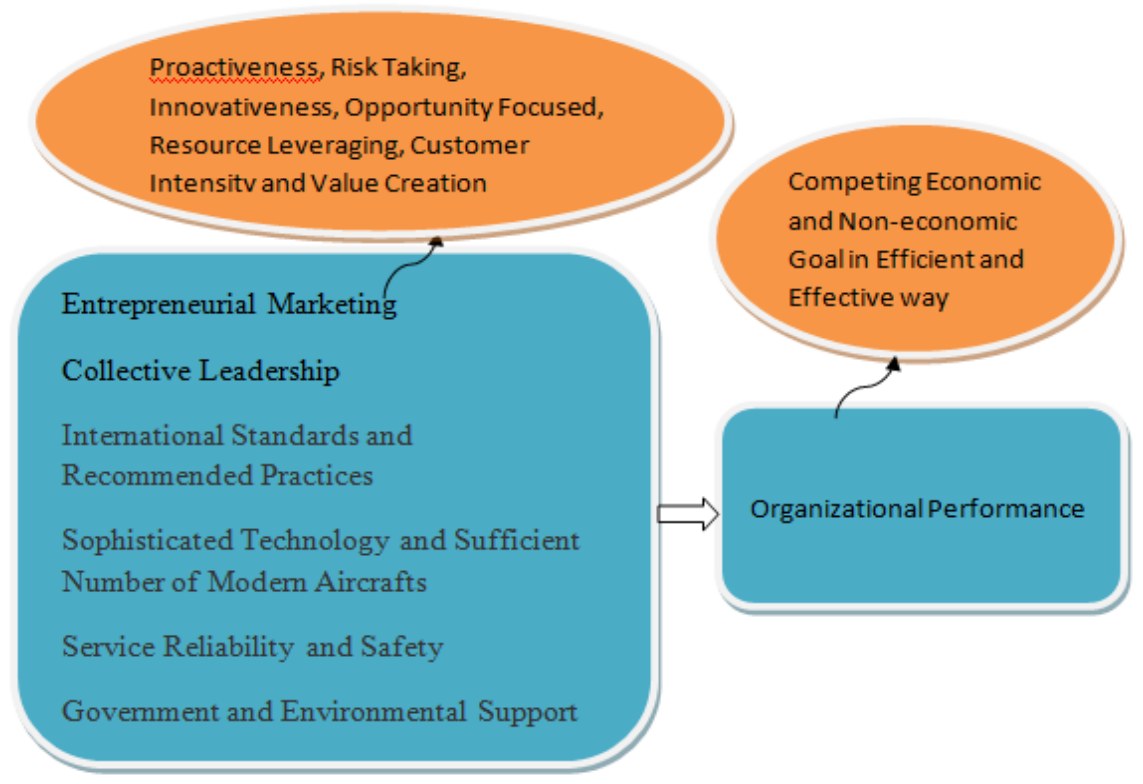

Independent Variables

Dependent Variable

Figure 7. NAC Performance Framework

Source: Authors' recommendation on the basis of study

A performance framework of NAC is proposed for achieving economic and non-economic goal effectively and efficiently. The relationship between independent variables and dependent variable has been shown. The key determinants of better performance in airlines business as independent variables are entrepreneurial marketing (proactiveness, risk taking, innovativeness, opportunity focused, resource leveraging, customer intensity and value creation), collective leadership, international standards and recommended practices of aviation business, sophisticated technology and sufficient number of modern aircrafts, service reliability and safety, and government and environmental support. These dimensions would succeed airline business in turbulent market situation due to changing technology, need of customers and intense competitive situation in global market. Organizational performance as dependent variable indicates the achievement of economic and non economic goal effectively and efficiently.

Customer intensive approach and customer value creation efforts are important elements for airlines passenger satisfaction as these factors are more relevant to service industries. Proactive attempts, calculating risk taking behavior, innovations in product/service and business operational process, and effective utilization of available resources are key elements to succeed the business in the present global competitive environment. Collective leadership has significant impact in public company where a governing body is responsible for business operation. Strict application of international standard and recommended practices as prescribed by ICAO (International Civil Aviation Organization, 2007; Mackenzie, 2010) is a special provision for operation of aviation industry. The advanced and sophisticated technology, and availability of sufficient number of modern aircrafts are needed to maintain the service reliability, punctuality and safety. These elements are more sensitive to maintain the customer trust and their loyalty. The internal and external environmental support is essential to succeed the airlines business in the present competitive business world (Mitchell, 2002).

\section{Conclusion}

The performance of NAC was found in the similar direction of worldwide aviation business so that it can be concluded that NAC has been providing average level of services as compared to global aviation industry in terms of revenue generation, retention of market share, maintaining load factor and contribution to national GDP. On the basis of qualitative data analysis, NAC has minimum number of aircrafts as the result of lack of ownership feeling by the government. Similarly, poor interdepartmental coordination and irresponsibility of some staffs are observed as the outcome of polarization of political alignment in staff union. Appreciative Inquiry Training, Customer Care and Hospitality Management Training and such other motivational training are 
recommended for better departmental coordination and staffs' responsibility feeling attitude. Similarly, fair practice of reward and punishment system on the basis of staff performance appraisal, without any biasness (good person instead of our person), is recommended. Merit based human resource management would be practiced to improve the staff loyalty and performance efficiency.

NAC Performance Framework is designed and recommended to adopt the given variables for growth and development of Nepal Airlines. Six components of framework are entrepreneurial marketing, collective leadership, international standards and recommended practices, sophisticated technology and sufficient number of modern aircrafts, service reliability and safety, and government and environmental support.

NAC should prepare long term strategic plan, side by side successful implementation of Three Years Improvement Plan, to capture the growing market of airline business as airline passenger will be double in 2035 (IATA's 20-years air passenger forecast). It is essential to become a member of airlines business network by improving the safety issues of Nepalese airlines. Similarly, for soundness on collective leadership, experienced and professional members are to be appointed in the company board instead of political quota fixing practice. As a government owned airlines, NAC should continue remote flights for fulfillment of social responsibility. A recommendation is made to conduct the study with some other airlines companies so that the result can be generalized in aviation business that will fulfill the limitation of this study.

\section{References}

Alotaibi, M. M. (2015). Evaluation of AIRQUAL scale for measuring airline service quality and its effect on customer satisfaction and loyalty (Doctoral dissertation). Cranfield University, UK.

Antony, J. P., \& Bhattacharya, S. (2010). Measuring organizational performance and organizational excellence of SMEs - Part 2: an empirical study on SMEs in India. Measure Business Excellence, 14(3), 42-52. https://doi.org/10.1108/13683041011074209

Barata, J. M. M., \& Neves, F. M. S. P. (2017). The history of aviation education and trainng. Open Journal of Applied Science, 7, 196-205. https://doi.org/10.4236/ojapps.2017.74017

Basol, E., \& Dogerlioglu, O. (2014). Structural determinants of organizational effectiveness. Journal of Organizational Management Studies, 273364, 13. https://doi.org/10.5171/2014.273364

Becherer, R. C., Helms, M. M., \& McDonald, J. P. (2012). The effect of entrepreneurial marketing on outcome goals in SMEs. New England Journal of Entrepreneurship, 15(1). https://doi.org/10.1108/NEJE-15-01-2012-B001

Bista, R. (2009). Tourism policy, possibilities and destination service quality management in Nepal (Doctoral dissertation). University of Macedonia, Greece.

Chandarasorn, V. (2014). State administration and promoting good governance. Journal of Shinawatra University, 1(1), 1-16.

Civil Aviation Authority of Nepal. (2013). Annual Report 2013. Kathmandu: CAAN.

Dragnić, D. (2014). Impact of internal and external factors on the performance of fast-growing small and medium business. Management, 19(1), 119-159.

Florian, G. I. (2013). Understanding the determinants of firms' performance. SEA-Practical Application of Science, 1(2).

Gavrea, C., Illies, L., \& Stegerean, R. (2011). Determinants of organizational performance: the case of Romania. Management \& Marketing Challenges for the Knowledge Society, 6(2), 285-300.

Gurung, H. (2013). Silver lining in the Nepal sky. Nepali Times, 662. Retrieved from http://nepalitimes.com/article/nation/Nation-sliver-lining-in-the-Nepal-sky,521

Hacioglu, G., Even, S. S., Even M. S., \& Celikkan, H. (2012). The effect of entrepreneurial marketing on firm's innovative performance in Turkish SMEs. $8^{\text {th }}$ International Strategic Management Conference. https://doi.org/10.1016/j.sbspro.2012.09.1065

Hamali, S. (2015). The effect of entrepreneurial marketing on business performance: small and garment industry in Bandung city Indonesia. Developing Country Studies, 5(1), 24-29.

Hansen, G. S., \& Wernerfelt, B. (1989). Determinants of firm performance: the relative importance of economic and organizational factors. Strategic Management Journal, 10(5), 399-411.

https://doi.org/10.1002/smj.4250100502 
Himalayan News Service. (2016, December 14). Ban on Nepali airlines to EU countries to stay. The Himalayan Times, XVI (22), 5.

International Air Transport Association. (2016). Economic Performance of the Airlines Industry. Retrieved from www.iata.org/economics

International Civil Aviation Organization. (2007). Annexure: International Standard and Recommended Practice. Montreal: ICAO.

Ismail, N. A., \& Jenatabadi, H. S. (2014). The Influence of Firm Age on the Relationship of Airlines Performance, Economic Sustain and Internal Operation. Transportation Research Part A: Policy and Practice, 212-224. https://doi.org/10.1016/j.tra.2014.06.010

Jackson, T. (2015). 18 Key performance indicator examples defined for Managers. Clear Point Strategy. Retrieved from https://www.clearpointstrategy.com/18-key-performance-indicator

Jenatabadi, H. S. (2015). An Overview of Organizational Performance Index: Definition and Measurement. https://doi.org/10.2139/ssrn.2599439

KC, R. B. (2010). IATA's 2010 forecast and purchase of aircraft for Nepal Airlines. Aakash Bhairab, 29(1), 1-3.

Kilenthong, P. (2011). An empirical investigation of entrepreneurial Marketing and the role of entrepreneurial orientation (Doctoral dissertation). University of Illinois, Chicago.

Lama, V. (2014). New planes new hope. Nepali Times. Retrieved from https://www.Nepalitimes.com/article/nation/new-planes-new-hope, 1339

Ma, Y., Kim, M., Heo, J., \& Jang, L. (2012). The effect of entrepreneurship and market orientation on social performance of social enterprise. 2012 International Conference on Economics Marketing and Management, IPEDR, 28, 60-65.

Mackenzie, M. (2010). ICAO: A History of the International Civil Aviation Organization. University of Toronto Press. https://doi.org/10.3138/9781442670143

Mitchell, H. (2002). Strategic worth of human resource: Driving organizational performance. 2002 Human resource conference. Universialia. Retrieved from http://www.universalia.com/sites/default/files/presentations/fichiers/2002_strategicworthhr_hughmitchell.p df

Moghimi, M., \& Ahmadpour, D. M. (2007). The entrepreneurial training of small and medium-sized businesses, needs and solutions. Journal of Entrepreneurship Development, 1(1), 207-245.

Morris, M. H., Schindehutte, M., \& LaForge, R. W. (2002). A Construct for integrating emerging entrepreneurship and marketing perspectives. Journal of Marketing Theory and Practice (Fall), 10(4), 1-19. https://doi.org/10.1080/10696679.2002.11501922

Mudashiru, A., Bakare, A. O., Babatunde, Y., \& Ishmael, O. L. (2014). Good corporate governance and organizational performance: an empirical analysis. International Journal of Humanities and Social Science, $4(7), 1$.

Mwangi, H. W., \& Bwisa, H. (2013). The effect of entrepreneurial marketing practice on the growth of hair salons: a case study of hair salon in Kambu Township. International Journal of Academic Research in Business and Social Science, 3(5), 467-480.

Nepal Airlines Corporation. (2016). Annual Report FY 2061/62 to 2072/73. Kathmandu: NAC.

Nepal Government. (2010). Nepal Airlines Corporation Act 2019. Kathmandu: Ministry of Law, Justices and Parliament, Nepal Government. Retrieved from www.lawcommission.gov.np

Nepal Government. (2016). Nepal Tourism Statistics 2015. Kathmandu: Ministry of Culture, Tourism and Civil Aviation.

Nepal Rastra Bank. (2015). Macroeconomic Indicators of Nepal. Katmandu: NRB.

Parajuli, B. K., \& Paudel, Y. R. (2014). Impact of Nepal tourism year 2011 on tourist arrival in Pokhara. Himalayan Journal of Sociology and Antropology, VI, 22-50. https://doi.org/10.3126/hjsa.v6i0.10687

Petrescu, R. V. V., Aversa, R., Akash, B., Bucinell, R., Corchado, J., Berto, F., .. Petrescu, F. I. T. (2017). History of aviation - a short review. Journal of Aircraft and Spacecraft Technology. https://doi.org/10.3844/jastsp.2017.30.49 
Pokhrel, T. (2015). Poverty in Nepal: characteristics and challenges. Journal of Poverty, Investment and Development, 11, 44-55.

Right Management. (n.d.). Organizational effectiveness: discovering how to make it happen. Leadership Insight. Retrieved from https://eoeleadership.hee.nhs.uk/sites/default/files/1317116794_DGgD_organisational_effectiveness_how_t o_make_it_happ.pdf

SaeediKia, M. (2007). Principles of Entrepreneurship. Tehran: Kia Publications, 13.

Sarma, M., Septiani, S., Dewi, F. R., \& Siregar, E. H. (2013). Impact of entrepreneurial marketing and business development on business sustainability: small and household footware industries in Indonesia. International Journal of Marketing Studies, 5(4), 110-122. https://doi.org/10.5539/ijms.v5n4p110

Shah, C. M. (2012). Maile sewa prabes garda ra ahileko awasta, Aaksh Bhairab, 31(1), 30.

Shresta, R. (2011). Nepal bayu sewa nigamka kamjori pakshyaharu, Aakash Bhairab, 30(1).

Subedi, A. (2016). Tin barse sudhar karyayojanale jagayeko asa: ke chha sudhar ayojanama. Aakash Bhairab, 63-64.

Tyler, T. (2016). A historic year IATA and its members. Annual Review 2016. Retrieved from www.iata.org/2016-review

Wiklund, J. (1999). The sustainability of the entrepreneurial orientation - performance relationship. Entrepreneurship Theory and Practice, 24(1), 37-48. https://doi.org/10.1177/104225879902400103

Wittmer, A., Bieger, T., \& Muller, R. (2011). Aviation System: Management of the Integrated Aviation Value Chain. Springer Berlin Heidelberg. https://doi.org/10.1007/978-3-642-20080-9

Yang, C. (2006). The Effect of Leadership and Entrepreneurial Orientation of Small and Medium Enterprises on Business Performance in Taiwan (Doctoral dissertation). University of the Incarnate World.

\section{Copyrights}

Copyright for this article is retained by the author(s), with first publication rights granted to the journal.

This is an open-access article distributed under the terms and conditions of the Creative Commons Attribution license (http://creativecommons.org/licenses/by/4.0/). 